\title{
O PROJETO ESCOLA “SEM" PARTIDO COMO UMA FALSA PROJEÇÃO DO CAMPO EDUCACIONAL
}

\section{THE ESCOLA SEM PARTIDO PROJECT AS A FALSE PROJECTION OF THE EDUCATIONAL FIELD}

\author{
Michel Pisa Carnio ${ }^{1}$ \\ Marcos Cesar Danhoni Neves ${ }^{2}$
}

\begin{abstract}
Resumo
O presente trabalho visa colaborar com elementos teórico-metodológicos para analisar o clima de preconceito e intolerância que permeiam o projeto de lei intitulado Escola Sem Partido, assim como suas implicações para o campo educacional. Por meio de apropriações psicanalíticas dos pensadores da Escola de Frankfurt, em especial Theodor Adorno e Max Horkheimer, buscamos fundamentos nos estudos sobre a personalidade autoritária para propor interpretações que revelem toda a estereotipia, a exclusão do diferente, a fragilidade do ego e o caráter antidemocrático que permeiam o referido projeto. Destacamos o projeto Escola Sem Partido como uma falsa projeção do campo educacional, com a presença de muitos indícios de pensamento autoritário direcionado à educação.
\end{abstract}

Palavras-chave: Escola Sem Partido; Pensamento autoritário; Educação e barbárie; Teoria Crítica.

\begin{abstract}
The present work aims to collaborate with theoretical and methodological elements to analyze the climate of prejudice and intolerance that permeate the bill titled Escola Sem Partido, as well as its implications for the educational field. Through the psychoanalytic appropriations of the thinkers of the Frankfurt School, especially Theodor Adorno and Max Horkheimer, we have sought grounds in the studies on the authoritarian personality to propose interpretations that reveal all the stereotypy, the exclusion of the different, the fragility of the ego and the antidemocratic character that permeates the referent project. We highlight the project Sem School as a false projection of the educational field, with the presence of many indications of authoritarian thought directed to education.
\end{abstract}

Keywords: Unpolitical Schools; Authoritarian thinking; Education and barbarismo; Critical Theory.

\footnotetext{
${ }^{1}$ Professor adjunto do depto. de metodologia do ensino da UFSCAR - michelcarnio@ yahoo.com.br

${ }^{2}$ Professor do centro de ciências exatas do depto. de Física da UEM - macedane@ yahoo.com
} 


\section{DEVIR EDUCAÇÃO}

ISSN: 2526-849X

\section{Introdução}

O presente trabalho é fruto de um projeto de pós-doutorado finalizado cujo objetivo geral foi colaborar com elementos teórico-metodológicos para analisar a confluência da racionalidade instrumental com o clima de preconceito e intolerância social, e a forma como estes elementos repercutem em concepções e discursos equivocados sobre a educação na sociedade contemporânea. Para isso, propomos uma articulação entre elementos da psicanálise frankfurtianas (em especial Theodor Adorno e Max Horkheimer) e sua sistematização por Campanholo (2014) quanto à apropriação freudiana na intepretação do pensamento autoritário, para então materializarmos uma apropriação destes referenciais que possa contribuir com elementos teórico-metodológicos para discutir o projeto de lei intitulado "Escola Sem Partido".

\section{O Projeto Escola Sem Partido}

Nos últimos anos têm se intensificado debates em torno deste projeto. Ele foi proposto inicialmente em 2004, posteriormente arquivado na Câmara dos Deputados e, recentemente, colocado na pauta do dia por meio do Projeto de Lei $n^{\circ}$ 867/2015. Apesar de considerado inconstitucional pelo parecer do Ministro do STF Luís Roberto Barroso ${ }^{3}$, o projeto continua tramitando em várias câmaras legislativas municipais e estaduais do Brasil. Justificado em seu site oficial como uma "reação ao fenômeno da instrumentalização do ensino para fins político-ideológicos, partidários e eleitorais"4, seu movimento vem causando reações preocupantes do ponto de vista de uma educação democrática, que envolvem, entre outras coisas, o cerceamento dos conteúdos lecionados e a perseguição e criminalização da prática docente.

Pesquisas recentes reiteram que o Escola Sem Partido se utiliza de uma "linguagem próxima do senso comum, recorrendo a dicotomias simplistas que reduzem questões complexas a falsas alternativas" (PENNA, 2017). Ele constitui um "instrumento estratégico

\footnotetext{
3 "Medida Cautelar da Inconstitucionalidade da Escola sem Partido" do ministro Luís Roberto Barroso, referente à Lei 7.800/2016 do Estado de Alagoas. Disponível em:

$<$ http://www.educadores.diaadia.pr.gov.br/arquivos/File/pdf/medida_cautelar_inconstitucionalidade_escola_part ido.pdf $>$.

${ }^{4}$ Disponível em: <http://escolasempartido.org/midia/395-entrevista-de-miguel-nagib-a-revista-profissaomestre>.
} 


\section{OO DEVIR EDUCAÇÃO}

ISSN: 2526-849X

de mobilização e propaganda" e pretende, mesmo sem vigência jurídica, ser um "instrumento jurídico-político de controle da escola" (ALGEBAILE, 2017). Trata-se da "proposição de ideias supostamente neutras, mas que escondem, na verdade, um teor fortemente persecutório, repressor e violento" (RAMOS, 2017).

Populista e sensacionalista, o movimento consegue canalizar as frustrações de uma população cansada dos malfazeres cotidianos e da sensação de um mundo em permanente desencantamento - sensação frequentemente reforçada e alimentada pela banalização da (in)formação nas mídias virtuais. Nos seus apoiadores, nota-se tendências de posicionamento agressivo e intolerante que, ao invés de incentivarem o debate e a construção coletiva dos melhores caminhos para trilhar a educação nacional, fecham-se ao diálogo e procuram sempre impor o seu ponto de vista a quem pensa diferente.

Compreendendo então essa crise da educação não como algo pontual, mas como fruto de uma racionalidade instrumental e autoritária que permeia a sociedade, nos voltamos aos estudos da Personalidade Autoritária da década de 50 (ADORNO et al., 1965) e outros estudos de Theodor Adorno, tendo em vista tanto sua atualidade (CROCHÍK, 2011; CARONE, 2012; BUENO, 2013, CAMPANHARO, 2014) quanto sua necessária apropriação crítica e não anacrônica (LASTÓRIA, 2017).

\section{A personalidade autoritária para a Teoria Crítica: contribuições da psicanálise}

Em linhas gerais, Adorno e Horkheimer supõem que a relação com a natureza, característica da sociedade burguesa, é determinada pelo medo do homem face às forças naturais desconhecidas. A racionalidade que se formou ao longo desse processo empenhou-se em libertar os homens do medo e elevá-los à posição de senhores (ADORNO; HORKHEIMER, 1985, p. 17). Esse processo é denominado pelos autores de esclarecimento.

Porém, "do medo o homem presume estar livre quando não há nada mais de desconhecido" (ADORNO; HORKHEIMER, 1985, p. 26).

Isso teria levado os homens a desenvolverem procedimentos mais contundentes para assegurar a sua sobrevivência. Nesse sentido, o saber se tornou poder, pois foi procurando entender as leis da natureza que os homens engendram seu poder sobre ela. Em compensação, o saber predominante acabou transformando a natureza em substrato para a dominação. (CAMPANHARO, 2014, p. 119). 


\section{DEVIR EDUCAÇÃO}

ISSN: 2526-849X

Assim, na relação entre o homem e a natureza,

[...] o esclarecimento se comporta com as coisas como o ditador se comporta com os homens. Este conhece-os na medida em que pode manipulá-los. O homem de ciência conhece as coisas na medida em que pode fazê-las [...] Nessa metamorfose, a essência das coisas revela-se como sempre a mesma, como substrato da dominação. (ADORNO; HORKHEIMER, 1985, p. 21).

Para Adorno e Horkheimer, essa relação com a natureza só se concretizou mediante a abstração, ou seja, pela redução da multiplicidade, pela eliminação das qualidades, pela destruição das distinções. Neste sentido, “[...] o indivíduo burguês só se entrega à natureza de acordo com a máxima da autoconservação, ou seja, na medida em que pode dominá-la" (CAMPANHARO, 2014, p. 120).

[...] até mesmo o ego, [...] é na verdade, ao mesmo tempo, o produto e a condição da existência material [...] Ao longo das gerações, o ego se expande e se contrai com as perspectivas da autonomia econômica e da propriedade privada. Finalmente, ele passa dos burgueses desapropriados para os donos-de-trustres totalitários, cuja ciência acabou por se reduzir ao conjunto de métodos de reprodução da sociedade de massas submetida. (ADORNO; HORKHEIMER, 1985, p. 75).

Adorno e Horkheimer (1985) compreendem a racionalidade (ou esclarecimento) como uma fuga do medo do desconhecido, onde a Odisseia de Homero representaria o protótipo do indivíduo burguês. Ao se atar ao mastro para ouvir o canto da sereia sem sofrer as consequências, Homero expõe a artificialidade da razão na compreensão do mundo e o papel da formação do Ego tanto como adaptação e autonomia quanto como racionalização mecanismo de defesa que resguarda o ego de sua fragilidade.

Mas, ao se deixar amarrar, Ulisses cria o meio de se autoconservar. Ou seja, ele se relaciona com o prazer de uma forma racional, a fim de garantir a sua conservação. Nesse sentido, [...] a autoconservação do sujeito também consiste no domínio sobre a natureza interna (CAMPANHARO, 2014, p. 121).

Para os pensadores alemães, o progresso da civilização ocidental acentuou a dominação como princípio da autoconservação, sendo a sociedade burguesa a maior expoente desse processo. Ela "maximizou a dominação sobre a natureza, baseada no domínio sobre os 


\section{DEVIR EDUCAÇÃO}

ISSN: 2526-849X

demais homens. Mas, também forçou a dominação de cada um sobre si mesmo, mediante a imposição da autoconservação ao princípio do prazer (CAMPANHARO, 2014, p. 123).

Enquanto para os frankfurtianos "perceber é projetar" (ADORNO; HORKHEIMER, 1985, p. 175), derivam certos problemas quando esta percepção não está alinhada aos conteúdos de verdade da realidade. Na falsa projeção da realidade ocorre que, ao invés da interiorização do imperativo social (cultura) na estrutura psíquica do sujeito - e posterior adequação desta àquela -, tem lugar a identificação pronta e imediata da consciência com as escalas de valores estereotipadas alimentadas pelo próprio sujeito. Essa incapacidade de internalização do superego "[...] se deve a uma fraqueza do ego, à sua incapacidade para realizar a síntese necessária, isto é, para integrar o superego consigo mesmo (ADORNO et al., 1965, p. 239).

Coloca-se assim como questão central do estudo da Personalidade Autoritária refletir por que as pessoas atentam contra seus próprios interesses. Utilizada em seu estudo, Adorno construiu a Escala $\mathrm{F}$, que era composta por nove disposições: a submissão autoritária, a agressividade autoritária, o convencionalismo, a projetividade, a anti-intracepção, a preocupação com o comportamento sexual das pessoas, a valorização do poder e da dureza, a superstição e a estereotipia, a destrutividade (ou visão catastrófica do mundo) e o cinismo.

Os dois primeiros traços são do caráter sado-masoquista, ou seja, do sujeito que se submete incondicionalmente à autoridade (masoquismo), e descarrega a agressividade nos grupos de contra-identificação (sadismo). A antiintracepção é a dificuldade do sujeito entrar em contato com a sua vida psicológica e desvalorizar sentimentos, emoções, ternura, sensibilidade, como se fosse, por isso, muito racional. Daí também decorre a sua valorização do poder e da dureza (quem é duro consigo mesmo, também o é com os demais); a projetividade é resultado de pulsões proibidas e negadas pelo sujeito que, no entanto, são exteriorizadas pela atribuição a outrem; a preocupação com o comportamento sexual das pessoas decorre tanto do sado-masoquismo como da projetividade, como se os outros realizassem as "sujeiras" que gostariam mas estão impedidos de realizar, etc. (CARONE, 2012, p. 19).

Em reflexão análoga, e sendo a educação elemento fundamental de emancipação, visamos analisar a maneira como as ideias do Escola Sem Partido vão contra as vertentes educacionais que prezam pela construção de consciências críticas e autônomas. Para isso, nos apropriamos do estudo de Campanharo (2014) sobre as apropriações freudianas por Adorno 


\section{DEVIR EDUCAÇÃO}

ISSN: 2526-849X

ao estudar o pensamento autoritário, visando "entender as condições subjetivas que facilitam o indivíduo aderir favoravelmente opiniões, valores e atitudes contrários à sua emancipação" (CAMPANHARO, 2014, p. 107).

\section{Escola sem Partido como falsa projeção educacional}

Fundamentado nas mobilizações freudianas da psicanálise, para Adorno o Ego seria o responsável pela síntese entre as próprias instâncias psíquicas e entre elas e o mundo externo. A manifestação dos desejos e vontades do Id nem sempre são concretizadas no conjunto de normas e valores morais compartilhados pela sociedade, trazendo elementos de frustração ao eu. Quando, em sua constituição, o Ego carece de maturidade, perde a capacidade de crescer no confronto entre suas ideias e realidade, retira do Superego seu status de orientação cognitiva e o renega a um corpo estranho.

[...] a fraqueza do ego pareceria coexistir no convencionalismo e no autoritarismo. A fraqueza do ego [...] é aparentemente este estado de coisas que cria no indivíduo a necessidade de buscar um agente organizador e coordenador fora de si mesmo. Quando se depende de tais agentes exteriores para tomar as decisões morais, pode dizer-se que a consciência está exteriorizada (ADORNO et al., 1965, p. 239).

Adorno e colaboradores (1965) definiram a variável "Projetividade" como a “disposição a crer que no mundo acontecem coisas desenfreadas e perigosas; a projeção para o exterior de impulsos emocionais inconscientes" (ADORNO et al. 1965, p. 234). A projeção constitui o mecanismo da agressão autoritária e está presente em outras variáveis da Escala-F. Ela é identificada como mecanismo essencial do indivíduo antidemocrático na medida em que responde a uma necessidade profunda que leva à distorção dos fatos.

O que o indivíduo antidemocrático sente necessidade de distorcer é algumas tendências profundas. Adorno et al. explicam que elas correspondem a impulsos recalcados, ou seja, pulsões do Id. O indivíduo projeta os impulsos indesejáveis sobre outro indivíduo recusando, assim, a responsabilidade pela sua origem. Com isso, ao invés de sentir-se culpado, atribui a sua culpa a outro (CAPANHARO, 2014, p. 143).

Essa tendência é interpretada também como uma das expressões da fraqueza do Ego.

Pois, “[...] a projeção é um meio para manter as pulsões do Id alienadas do Ego, e pode ser 


\section{OO DEVIR EDUCAÇÃO}

ISSN: 2526-849X

interpretada como signo da incapacidade do Ego em cumprir com suas funções" (ADORNO et al., 1965, p. 243). O Ego manifesta, mediante a projeção, a “[...] incapacidade de responsabilizar-se por tendências que lhe são próprias” (CAMPANHARO, 2014, p. 143).

[...] se uma pessoa sustenta que alguém abriga propósitos hostis contra ela, sem que existam provas da verdade de tal afirmação, há boas razões para suspeitar que seja ela mesma quem tem intenções agressivas e busca justificá-las mediante a projeção". (ADORNO et al., 1965, p. 243-244).

Adorno interpreta os impulsos sadomasoquistas em termos de uma condição ou ainda resultado da adaptação social. Segundo ele, “[...] a pauta segundo a qual tais gratificações se traduzem em traços de caráter é uma resolução específica do complexo de Édipo" (ADORNO et al., 1965, p. 708). Se por um lado o amor do filho pela mãe é censurado, por outro é gerado um ódio pelo pai, mas "[...] com a exigência de que a criança transforme o ódio em amor" (CAMPANHARO, 2014, p. 132).

[...] a conversão de ódio em amor, a tarefa mais difícil que o indivíduo deve cumprir em sua primeira etapa de desenvolvimento, nunca é realizada completamente com êxito. Na psicodinâmica do 'caráter autoritário', parte da agressividade recém mencionada fica absorvida e convertida em masoquismo, enquanto a porção restante é transformada em sadismo, o qual busca descarregar sobre aqueles com quem o sujeito não se identifica: em última instância, o exogrupo. (ADORNO et al., 1965, p. 708).

Com isso, o caráter autoritário hipervaloriza o endogrupo e censura o exogrupo. Portanto, além da estereotipia como meio de identificação social, a síndrome autoritária “[...] ocupa uma verdadeira função 'econômica' na própria psicologia do sujeito: ajuda-lhe a canalizar sua energia libidinosa em conformidade com as exigências de seu severo superego (ADORNO et al., 1965, p. 708). Isso também significa que “[...] o sujeito autoritário distorce a realidade, pois não explica historicamente a hierarquia social e a interpreta como uma espécie de castigo bem aplicado" (CAMPANHARO, 2014, p. 133).

Embora o paranoico está repleto de ódio geral, tende a 'escolher' seu inimigo, a importunar certos indivíduos que atraem sua atenção: por assim dizer, se enamora negativamente. Talvez ocorra algo similar com o fascista em potência. Tão logo que consegue uma contracatexia específica e concreta, a que lhe é indispensável para fabricar uma pseudorrealidade social, pode 'canalizar' sua agressividade que de outro modo fluiria 


\section{OO DEVIR EDUCAÇÃO}

ISSN: 2526-849X

livremente, e deixar de lado outros possíveis objetos de perseguição. (ADORNO et al., 1965, p. 574).

Neste sentido, é possível encontrar nos discursos em defesa do Escola sem Partido muitas alusões a certos grupos sociais que estariam deturpando o sistema educacional e fazendo da escola não um espaço de aprendizagem e formação, mas de um tipo de doutrinação política e ideológica atribuída ao governo do PT e ao campo da esquerda como um todo. Baseados geralmente em situações educacionais específicas de interpretação tendenciosa, seus apoiadores estabelecem argumentos que acabam servindo de perseguição de grupos que pensam diferente. Consolida-se esse panorama social onde prevalecem a dicotomia entre apoiadores e opositores ao projeto, o "nós contra eles", em consonância às categorias de endogrupo e exogrupo destacado por Adorno.

Esses elementos de ressentimento e pseudorrealidade mobilizados pela estrutura psíquica do ego fragilizado ajudam a compor um paradoxo: a maioria dos chamados exogrupos é objetivamente mais fraca se comparada aos grupos que estariam supostamente ameaçando (ADORNO et al., 1965). Ou seja, atribui-se um poder muito grande às supostas ameaças do pensamento hegemônico, poder esse que não condiz com sua possibilidade real de efetivação. Nos termos do Escola sem Partido tem sido comum escolher o professor como o maior inimigo a ser combatido na educação. Ele seria um ator que, nem sempre profissional e ético, se utilizaria da "audiência cativa" dos alunos em sala de aula para lhes impor suas vertentes de pensamento (políticas, ideológicas, morais, religiosas). Como já apontado por Adorno, existiria nesses casos um conflito permanente e insolúvel, no qual a sensação de ameaça não diminui mesmo que essa fraqueza seja percebida. $\mathrm{Na}$ visão do pensamento autoritário, isso se conforma como

[...] um enfrentamento entre um endogrupo que trata de manter ou recuperar sua posição justamente superior, e um exogrupo, ressentido por danos passados, que se esforça para infligir aos demais o que ele há padecido. (ADORNO et al., 1965, p. 158).

O estabelecimento de grupos cujas ideias ou existências devem ser constantemente deslegitimadas e rechaçadas, ao invés de discutidas e compreendidas, constitui a variável intitulada de "Superstição e Estereotipia", e refere-se à "crença na determinação sobrenatural do destino humano; [e na] inclinação a pensar através de categorias rígidas" (ADORNO et al., 


\section{DEVIR EDUCAÇÃO}

ISSN: 2526-849X

1965, p. 234). Essas

[...] explicações primitivas e demasiadamente simples sobre os sucessos humanos são resistências a dar razões a muitas das ideias e observações imprescindíveis para uma compreensão adequada: por seu grande conteúdo afetivo e por consistir em elementos que poderiam engendrar angústia, o ego fraco não pode incluí-las em seu esquema conceitual. Mas ainda é provável que o ego projete sobre o mundo exterior aquelas forças mais profundas da personalidade que não pode integrar em si mesmo. (ADORNO et al., 1965, p. 241).

Ao proceder dessa forma, o sujeito não deixa de fornecer explicações para o comportamento alheio, bem como para as causas dos fenômenos naturais, porém, suas explicações consistem em ideias estranhas e estereotipadas acerca desses temas. $\mathrm{Na}$ explicação baseada na superstição, deixa-se de discutir o mérito das questões, e passam a se elaborar categorias baseadas em visões distorcidas e radicalizadas sobre os assuntos, a partir da arbitrariedade das projeções realizadas. A superstição, quando reiterada, indica que o ego fragilizado abre mão de sua responsabilidade interpretativa, "[...] já poderia ter 'se dado por vencido', isto é, renunciado a ideia de que seria capaz de determinar a sorte do indivíduo vencendo as forças exteriores" (ADORNO et al., 1965, p. 241).

As tentativas de construir imagens educacionais degradantes e degradáveis a partir das quais oferecem uma solução pontual e simplista, faz do Escola Sem Partido um projeto tendencioso e ideológico que, além de estar alheio às principais discussões e diagnósticos da realidade educacional brasileira, não se coloca aberto ao diálogo com professores e especialistas que apresentem concepções diferentes acerca dos mesmos temas. Com a variável "Destrutibilidade e Cinismo", Adorno e colaboradores (1965, p. 236) visavam compreender a "hostilidade e vilipêndio geral da humanidade", sendo muito comum a atribuição de visões catastróficas de mundo (e, no caso, da educação) para fundamentar a veracidade e necessidade de se efetivar seus pontos de vista.

Corrobora com essa formulação a ideia de que "[...] o indivíduo antidemocrático guarda em seu interior fortes impulsos agressivos resultantes das numerosas imposições externas que limitam a satisfação de suas necessidades" (ADORNO et al., 1965, p. 242), de forma que há de se considerar a variável "Poder e Dureza". Consiste na

[...] preocupação pela dimensão domínio-submissão, força-fraqueza, dirigente-dirigido; identificação com as figuras que representam o poder;

Revista Devir Educação, Lavras, vol.3, n.1, p.76-88 jan./jun., 2019. 


\section{OO DEVIR EDUCAÇÃO}

ISSN: 2526-849X

exagero dos atributos convencionais do ego; valorização excessiva da força e da dureza. (ADORNO et al., 1965, p. 234).

O antidemocrático teria variadas formas de manifestar tais impulsos, porém daria vazão a eles deslocando-os para os exogrupos. "A indignação moral, a agressão autoritária e a agressão oculta constituem as expressões dos impulsos agressivos primitivos" (CAMPANHARO, 2014, p. 142).

Uma das principais consequências das categorias até agora explicitadas diz respeito à variável da "Anti-introspecção". Ela consiste na "oposição ao subjetivo, imaginativo e sentimental" (ADORNO et al., 1965, p. 234). Essa atitude se caracteriza como uma recusa do indivíduo possibilitar o pensamento em deixar os indivíduos refletirem por si sós, mas também a recusa dele mesmo em pensar os fatos de forma autônoma, com medo de perder o controle sobre suas emoções e revelar seu ser íntimo seja para si mesmo ou para outro. Em contrapartida há uma dedicação do pensamento para as tarefas práticas, pois eles consistiriam em algo agradável.

Para Adorno, no pensamento autoritário há uma tendência forte em evitar que as pessoas criem consciência de si mesmas. É uma atitude de desvalorização do humano e valorização do material. Isso a tal ponto que, em situações extremas, “[...] os humanos passam a ser meros objetos materiais que se manejam friamente, enquanto que os objetos materiais, agora investidos de atração emocional, recebem amorosos cuidados" (ADORNO et al., 1965, p. 240). Nessa atitude, o Ego fraco se manifesta pela “[...] impaciência ante o indivíduo subjetivo e afetuoso acompanhada de oposição a este" (ADORNO et al., 1965, p. 240).

Por fim, a variável "Sexo" representa a "preocupação exagerada pelos fatos 'sexuais"” (ADORNO et al., 1965, p. 234). Essa tendência evidencia "[...] uma sexualidade alienada do Ego" (ADORNO et al., 1965, p. 244), e se refere a um forte predomínio das contracatexias sexuais mediante o recalque, a formação reativa e a projeção" (CAMPANHARO, 2014, p. 144).

Adorno vincula a preocupação exagerada com a sexualidade às tendências à agressão autoritária e à projeção. Dessa forma, a variável que representa "uma forte inclinação a castigar os transgressores dos costumes sexuais (homossexuais, criminosos sexuais) [...]" (ADORNO et al., 1965, p. 244). Essa inclinação poderia 


\section{OO DEVIR EDUCAÇÃO}

ISSN: 2526-849X

com as autoridades do endogrupo, mas também sugere que o indivíduo recalca seus próprios desejos sexuais e corre o perigo de perder o domínio sobre eles. (ADORNO et al., 1965, p. 244).

No que se refere à projeção, a preocupação com "orgias sexuais", por exemplo, poderia ser uma desfiguração da realidade, “[...] mas o conteúdo sexual dificilmente poderia se projetar se no sujeito não atuassem inconscientemente e intensamente impulsos de índole semelhante" (ADORNO et, al., 1965, p. 244). Essa questão nos remete à preocupação o projeto Escola Sem Partido com temáticas relacionadas à sexualidade, remetendo-se frequente - e erroneamente - ao termo "ideologia de gênero" como forma de deslegitimar e criminalizar a discussão sobre temas que, embora sejam centrais para iniciativas formativas contra o preconceito e discriminação, são considerados tabus dentro de culturas alinhadas à variável que Adorno denominou "Convencionalismo".

\section{Considerações finais}

Em sua época, Adorno procurou refletir o mecanismo psíquico que está por trás de tanto ódio e intolerância do pensamento antissemita, assim como do pensamento autoritário em geral com quem é, age ou pensa diferente da onda hegemônica. Neste contexto, interpretamos o projeto Escola Sem Partido como uma falsa projeção do campo educacional, com a presença de muitos indícios de pensamento autoritário direcionado à educação, e de outros que ainda demandam sistematização por meio de fundamentações críticas condizentes com as questões educacionais contemporâneas.

Muitos materiais podem ser analisados para estabelecer um paralelo dessa caracterização com os elementos psíquicos e sociais que marcam o projeto Escola Sem Partido e seus apoiadores. Pesquisas em andamento e análises preliminares (CARNIO; NEVES, 2018) demonstram uma constelação de elementos permeada de: visões de senso comum pedagógico, partidarismo político, utilização de exemplos fantasmagóricos extremos como instrumento de despertar o medo na população, utilização de falácias que distorcem a relação entre interesse público e privado na educação/formação escolar, preocupação e confusão intencional em relação aos estudos sobre identidade de gênero (denominados de 


\section{DEVIR EDUCAÇÃO}

ISSN: 2526-849X

“ideologia”), paranoia e manipulação da realidade, entre outros. Esse empobrecimento dos indivíduos

[...] não significa que os mecanismos psíquicos tenham sido exterminados; ao contrário, significa que os mesmos foram retirados dos sujeitos pelos poderes sociais, contribuindo para maior eficiência do sistema. Assim, a irracionalidade faz parte do funcionamento social, e não mais somente corresponde às profundezas psíquicas do inconsciente individual. (GOMIDE, 2011, p. 131).

O diagnóstico severo em relação às possibilidades de pensamento crítico em uma época que estimula a apropriação superficial e enviesada da realidade traz consigo a necessidade de se ampliar espaços e debates de discussão a respeito das contribuições do pensamento filosófico e psicanalítico para a compreensão e intervenção dos fenômenos educacionais atuais. Apesar de formuladas na década de 40, as apropriações psicanalíticas adornianas e suas formulações sobre o pensamento autoritário apresentam grande potencial para a construção de diagnósticos contemporâneos sobre as recentes políticas educacionais brasileiras, em especial o Escola Sem Partido. Entretanto, é premente a necessidade por atualização dos referenciais críticos e prol da acuidade e contemporaneidade da crítica e das formas de intervenção no campo educacional.

\section{Agradecimentos}

Agradecimento à CAPES pelo financiamento.

\section{Referências}

ADORNO, Theodor Wiesengrund.; FRENKEL-BRUNSWIK, E.; LEVINSON, D. J.; SANFORD, R. N. La Personalidad Autoritaria. Buenos Aires: Ed. Proyección, 1965.

ADORNO, Theodor Wiesengrund; HORKHEIMER, Max. Dialética do Esclarecimento. Trad. Guido Antonio de Almeida. Rio de Janeiro: Ed. Jorge Zahar, 1985.

ALGEBAILE, E. Escola sem Partido: o que é, como age, para que serve. In: FRIGOTTO, G. Escola "sem" partido: esfinge que ameaça a educação e a sociedade brasileira. Rio de Janeiro: UERJ/LPP, 2017. 
BUENO, Sinésio Ferraz. Theodor Adorno e Hannah Arendt: confluências no campo da filosofia da educação. Educar em Revista, Curitiba, Brasil, n. 49, p. 299-307, jul./set. Editora UFPR: 2013.

CAMPANHARO, Caroline. A recepção adorniana de Freud no estudo da personalidade autoritária. 2014. 164 p. Dissertação (Mestrado em Filosofia) - Universidade Federal do Espírito Santo, Centro de Ciências Humanas e Naturais, Vitória, 2014.

CARONE, Iray A Personalidade Autoritária: Estudos Frankfurtianos sobre o Fascismo. Revista Sociologia em Rede, v. 2, n. 2, Goiânia, 2012.

CROCHÍK, José Leon. Teoria crítica da sociedade e psicologia: alguns ensaios. Araraquara: Editora Junqueira e Marin, 2011.

GOMIDE, Ana Paula de Ávila. Psicanálise e Teoria Social à Luz da Teoria Crítica de Theodor W. Adorno. Revista Psicologia ciência e profissão, vol. 31, n. 1, 2011, pp. 120-133 2011.

LASTÓRIA, Luiz Antonio Calmon Nabuco. Ensaios de teoria crítica, ética e psicanálise. São Paulo: Nankin, 2017.

PENNA, F. O Escola sem Partido como chave de leitura do fenômeno educacional. In: FRIGOTTO, G. Escola "sem" partido: esfinge que ameaça a educação e a sociedade brasileira. Rio de Janeiro: UERJ, LPP, 2017.

RAMOS, M. N. Escola sem Partido: a criminalização do trabalho pedagógico. In: FRIGOTTO, G. Escola "sem" partido: esfinge que ameaça a educação e a sociedade brasileira. Rio de Janeiro: UERJ, LPP, 2017. 